\title{
Elucidating the Distribution and Speciation of Extraframework Species in BCsX Zeolite Catalysts for Styrene Production
}

\author{
Antonio J. Martín, ${ }^{[\mathrm{a}]}$ Sharon Mitchell, ${ }^{[\mathrm{a}]}$ Olivier Scholder, ${ }^{[\mathrm{b}]}$ René Verel, ${ }^{\left[{ }^{[a]}\right.}$ Roland Hauert, ${ }^{[\mathrm{c}]}$ Laetitia \\ Bernard,${ }^{[b]}$ Christopher Jensen, ${ }^{[\mathrm{d}]}$ Meinhard Schwefer, ${ }^{[\mathrm{d}]}$ and Javier Pérez-Ramírez ${ }^{*[\mathrm{a}]}$
}

\begin{abstract}
An improved understanding of the nature and distribution of extraframework species in BCsX zeolites is prerequisite to guide future developments in the environmentally attractive yet challenging production of styrene via the side-chain alkylation of toluene with methanol. Here, basic characterization and catalytic tests are complemented by integrated visualization through time-of-flight secondary ion mass spectrometry and energy-dispersive $\mathrm{X}$-ray spectroscopy and detailed assessment by ${ }^{133} \mathrm{Cs}$ and ${ }^{11} \mathrm{~B}$ nuclear magnetic resonance spectroscopy, to correlate the properties and performance during the successive ion exchange and impregnation steps in the preparation of both powders and millimeter-sized granules. The results highlight a significant impact of catalyst scale up on the effective introduction of boron species, originating chemical heterogeneity that is linked to selectivity losses. They also illustrate the complexity of elucidating the role of this modifier, which interacts with cesium cations and exhibits different coordination states and chemical environments depending on the pretreatment.
\end{abstract}

\section{Introduction}

Zeolites offer seemingly limitless potential as catalysts owing to the structural diversity of their crystalline frameworks, tunable composition, and the possibility to integrate hierarchical pore networks to enhance molecular transport.[1-4] Apart from controlling the type and ratio of framework metals, the functionality can be tailored through the introduction of various extraframework species.[4-7] An example of a challenging reaction where the application of basic multicomponent zeolite catalysts has proved critical is the side-chain alkylation of toluene with methanol. This reaction attracts interest as a sustainable one-step alternative to the current two-step route for the manufacture of styrene via the alkylation of benzene with

\footnotetext{
[a] Dr. A.J. Martín, Dr. S. Mitchell, Dr. R. Verel, Prof. J. Pérez-Ramírez ETH Zurich, Department of Chemistry and Applied Biosciences Institute for Chemical and Bioengineering

Vladimir-Prelog-Weg 1, 8093 Zurich (Switzerland)

E-mail: jpr@chem.ethz.ch

[b] Dr. O Scholder, Dr. L. Bernard

Empa, Department of Materials meet Life

Laboratory for Nanoscale Material Science

Überlandstrasse 129, 8600 Dübendorf (Switzerland)

[c] Dr. R. Hauert

Empa, Department of Advanced Materials and Surfaces

Laboratory for Joining Technologies \& Corrosion

Überlandstrasse 129, 8600 Dübendorf (Switzerland)

[c] Dr. C. Jensen, Dr. M. Schwefer

ThyssenKrupp Industrial Solutions AG

Friedrich-Uhde-Strasse 15, 44141 Dortmund (Germany)
}

ethene and sequential hydrogenation of the ethylbenzene product. The most effective catalytic systems identified to date comprise boron-modified cesium-exchanged X-type zeolites (BCsX).[8] The discovery of BCsX was primarily driven by screening the influence of varying the zeolite framework type and composition, and the type, amount, and method of introduction of extraframework species on the selectivity to sidechain (styrene, ethylbenzene) versus ring-alkylated (xylenes) products. Despite having been known for almost 40 years, to the best of our knowledge, this catalyst has not been applied in large scale, likely reflecting the modest toluene conversions (frequently $<10 \%$ ) achieved to date.

A number of efforts have attempted to characterize property-function relations over BCsX to guide the improved design.[9-14] These have largely applied standard techniques as X-ray diffraction, gas sorption, temperature-programmed desorption of $\mathrm{CO}_{2}$ or $\mathrm{NH}_{3}$, and infrared or ${ }^{27} \mathrm{Al}$ or ${ }^{29} \mathrm{Si}$ nuclear magnetic resonance spectroscopy. With few exceptions largepore, aluminum-rich faujasite-type zeolite $X$ exchanged with large alkali metal cations (e.g., $\mathrm{K}^{+}, \mathrm{Cs}^{+}, \mathrm{Rb}^{+}$) deliver the highest selectivity. Studies by in situ ${ }^{13} \mathrm{C}$ nuclear magnetic resonance (NMR) led to contradictory results, initially linking the high selectivity to transition-state shape selectivity,[10] but later to the specific interaction of methanol with the basic sites.[11] The latter was supported by in situ IR observation of the involvement of a unidentate formate species as an intermediate for sidechain alkylation.[12] In parallel, preliminary calculations indicated the requirement of a specific configuration of acidic and basic sites with steric restrictions.[13] Surprisingly, although known to play a key role in moderating the strength of basic sites, thereby enhancing the styrene/ethylbenzene ratio and suppressing the over oxidation of methanol to $\mathrm{CO}_{x},[15]$ little is known about the interaction with cesium and the nature and distribution of boron species, and how this is influenced by the method of introduction. This is likely due to the challenges associated with the often disordered and metastable nature and limited interaction with $\mathrm{X}$-rays or electrons.

This article reports a detailed assessment of the compositional and chemical homogeneity of BCsX catalysts, a knowledge of which is critical to optimize the incorporation of extraframework species. This is particularly relevant in view of the high manufacturing costs associated $(>34 \mathrm{wt} . \% \quad \mathrm{Cs}$ in a fully exchanged zeolite). Since scale up can influence the effective incorporation of extraframework species,[16] the catalysts are prepared in powder or granule form coupling appropriate postsynthetic treatments. The desired properties are confirmed by basic characterization and catalytic tests. Time-of-flight secondary ion mass spectrometry (ToF-SIMS) analysis yield correlative maps of all elements. The chemical identity of the Cs

This document is the accepted manuscript version of the following article:

Martín, A. J., Mitche11, S., Scholder, O., Vere1, R., Hauert, R., Bernard, L., ... Pérez-

Ramírez, J. (2017). Elucidating the distribution and speciation of boron and cesium in BCsX zeolite catalysts for styrene production. ChemPhysChem. http://doi.org/10.1002/cphc.201701086 
(a)

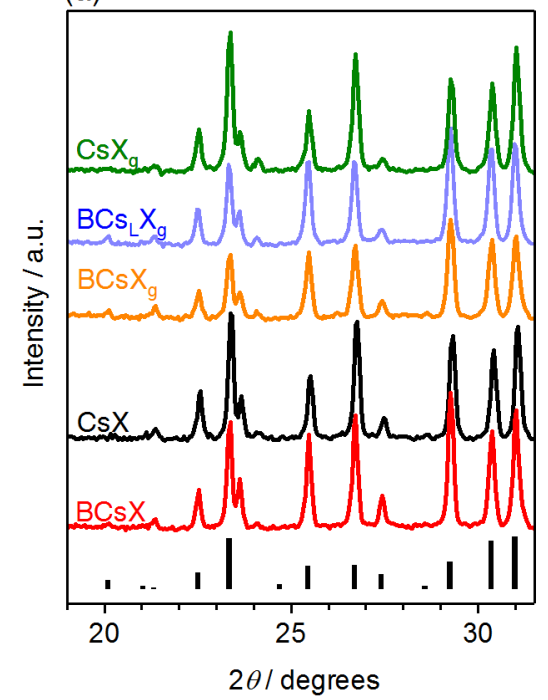

(b)

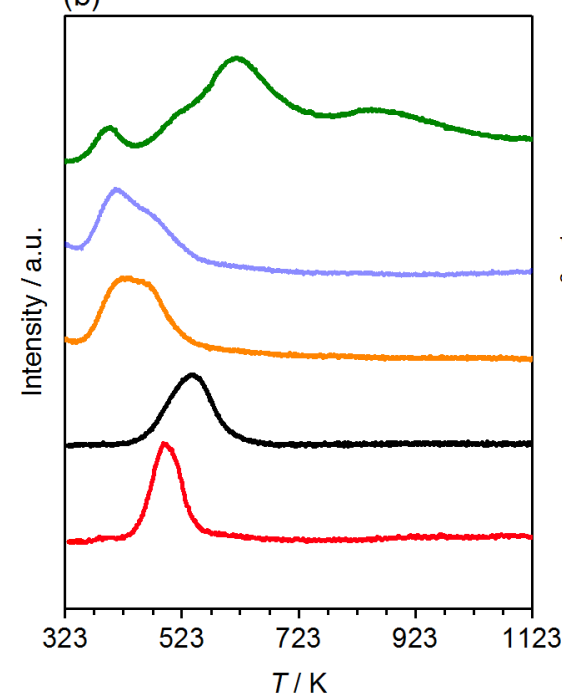

(c)

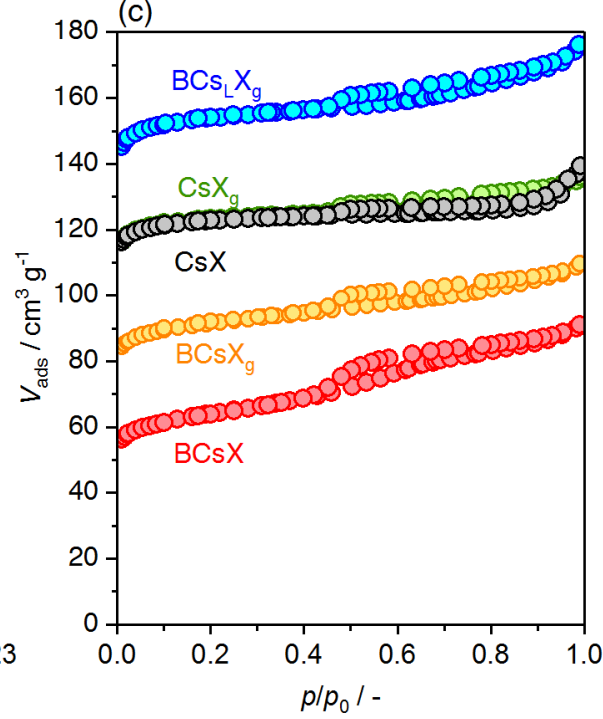

Figure 1. (a) XRD patterns, (b) $\mathrm{CO}_{2}$ desorption profiles, and (c) $\mathrm{N}_{2}$ isotherms of powder and granulated B-modified Cs-exchange zeolite $X$ catalysts. The corresponding Cs-X materials ( $\mathrm{CsX}$ and $\mathrm{CsX}$ ) prior to $\mathrm{B}$ incorporation are included for reference. Diffraction lines in (a) indicate the expected positions of reflections associated with CsX (JCPDS: 01-070-4282).

and B species is also probed by a comprehensive NMR spectroscopy analysis.

\section{Results and Discussion}

\section{Preparation and Evaluation of Benchmark Catalysts}

The benchmark BCsX catalyst was prepared by ion exchange of a commercial zeolite $X$ powder in sodium form $(\mathrm{NaX})$ with cesium (CsX) and the sequential introduction of boron by incipient wetness impregnation, adapting the protocol applied for the best-reported catalytic system to date. Nonetheless, we note that for ease of handling, post-synthetic modifications to optimize the properties of practical zeolites (e.g to enhance the porosity or introduce different metals) are often performed on the technical bodies,[17,18] which in turn could significantly impact their physicochemical properties and thus their effectiveness. In anticipation of a potential scale up of these materials, we thus

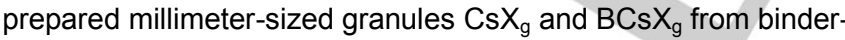
free commercial $\mathrm{NaX}$ granules by applying post-synthetic treatments parallel to those used for powder catalysts. Additionally, a milder Cs exchange procedure was applied over $B C s_{L} X_{g}$ aiming to observe the impact of the Cs exchange degree (see the Experimental section).

Physicochemical characterization of the bulk properties of the $\mathrm{NaX}, \mathrm{CsX}$, and BCsX powders evidenced the expected variation. X-ray diffraction (XRD) patterns confirm the successful substitution of a high fraction of $\mathrm{Na}$ with $\mathrm{Cs}$ in charge balancing positions, as reflected by the good match with the reference pattern of a cesium-exchanged zeolite $X$ (Fig. 1a). No change in the location of Cs was observed upon modification with $B$. Accordingly, the elemental composition determined by X-ray fluorescence (XRF) measurements (Table 1) reflected the incorporation of $\mathrm{Cs}$ and the decrease of the $\mathrm{Na}$ content close to the maximum exchange capacity (ca. $80 \%$ of exchangeable $\mathrm{Na}$ atoms[19]). Nevertheless, the addition of boron manifested in moderation of the basicity, as concluded from the weaker adsorption strength of $\mathrm{CO}_{2}$ (Fig. 1b) and in a decreased micropore volume (Fig. 1c and Table 1). According to the literature, boron in the form of $\mathrm{B}_{2} \mathrm{O}_{3}$ can selectively poison strong basic sites which are responsible for the dehydrogenation of formaldehyde to $\mathrm{CO}$ and $\mathrm{H}_{2}$, thereby enhancing the selectivity to styrene.[15,20] Parallel XRD results obtained from $B C s X_{g}$ confirmed the post-synthetic ion exchange (Fig. 1a). In tandem, the decrease of both the micropore volume and the strength and population of basic sites upon introduction of $B$ were also replicated over the granulated catalyst. In spite of these similarities, a lower degree of $\mathrm{Cs}$ incorporation on $\mathrm{BC} s_{\llcorner} \mathrm{X}_{\mathrm{g}}$ was evidenced by the larger micropore volume observed (Fig. 1c) and, more evidently, from an increased adsorption of $\mathrm{NH}_{3}$, indicating a larger population of $\mathrm{Na}^{+}$acid sites (Fig. S1).

Catalytic tests (Fig. 2) over sieved powder (see Experimental section) evidenced the preferential side-alkylation of toluene over CsX toward ethylbenzene, which was largely shifted toward styrene upon addition of the B modifier.[21,22] The distribution of alkylated products obtained over $\mathrm{CsX}_{\mathrm{g}}$ bore a strong resemblance to that over CsX. However, boron incorporation resulted in a milder promotion of the styrene route in this case, suggesting the influence of the particle arrangement on the postsynthetic modification. In tandem, the preferential formation of xylenes through ring-alkylation observed over $\mathrm{BCs}_{\llcorner} \mathrm{X}_{\mathrm{g}}$ associated to acidic zeolite catalysts $[9,23]$ highlighted the importance of attaining a high degree of Cs exchange. In this respect, experiments over partially-exchanged $\mathrm{NaY}$ catalysts determined a lower threshold of ca. $60 \%$ to favor side- over ringalkylation.[24] Basic characterization and catalytic tests thus confirmed the successful preparation of the benchmark powder catalyst and underscored potential challenges associated to the practical manufacturing of this type of modified zeolites. 


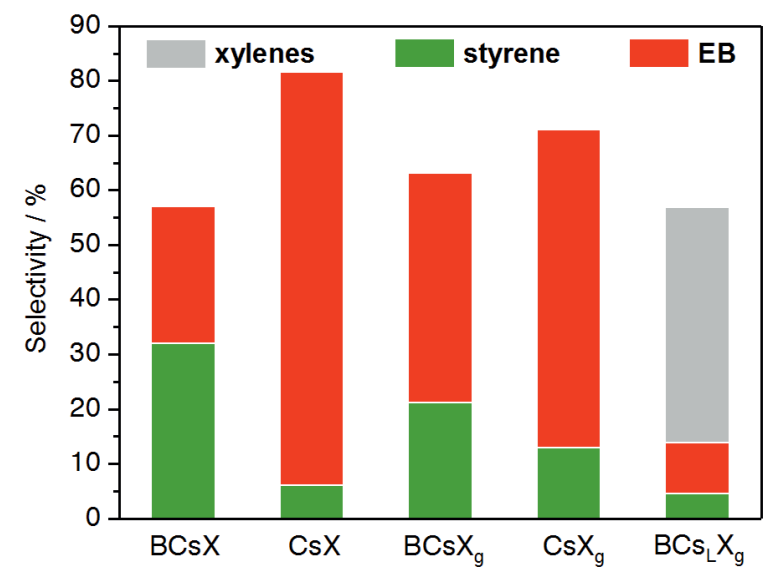

Figure 2. Selectivity to side-alkylated products over sieved powder and granulated catalysts. EB stands for ethylbenzene. Reaction conditions: $T=698 \mathrm{~K}, P=1$ bar.

Table 1. Composition and porous properties of the catalysts.

\begin{tabular}{|c|c|c|c|c|c|c|}
\hline Sample & $\begin{array}{c}\mathrm{Cs}^{[\mathrm{a}]} \\
(\mathrm{wt} . \%)\end{array}$ & $\begin{array}{c}\mathrm{Na}^{[\mathrm{a}]} \\
(\mathrm{wt} . \%)\end{array}$ & $\begin{array}{c}\mathrm{Si} / \mathrm{Al}^{[\mathrm{a}]} \\
\left(\mathrm{mol} \mathrm{mol}^{-1}\right)\end{array}$ & $\begin{array}{c}V_{\text {pore }}{ }^{[\mathrm{b}]} \\
\left(\mathrm{cm}^{3} \mathrm{~g}^{-1}\right)\end{array}$ & $\begin{array}{c}V_{\text {micro }}{ }^{[\mathrm{c}]} \\
\left(\mathrm{cm}^{3} \mathrm{~g}^{-1}\right)\end{array}$ & $\begin{array}{l}S_{\text {meso }}^{[c]} \\
\left(\mathrm{m}^{2} \mathrm{~g}^{-1}\right)\end{array}$ \\
\hline $\mathrm{NaX}$ & 0 & 23 & 1.3 & 0.29 & 23 & 60 \\
\hline CsX & 35 & 6 & 1.3 & 0.18 & 0.16 & 16 \\
\hline$B C s X$ & 31 & 7 & 1.3 & 0.17 & 0.15 & 15 \\
\hline $\mathrm{CsX}_{\mathrm{g}}$ & 31 & 8 & 1.3 & 0.21 & 0.18 & 27 \\
\hline$B C s X_{g}$ & 36 & 7 & 1.3 & 0.17 & 0.15 & 15 \\
\hline$B C s_{L} X_{g}$ & 29 & 11 & 1.3 & 0.28 & 0.23 & 35 \\
\hline
\end{tabular}

[a] XRF. [b] Volume of $\mathrm{N}_{2}$ adsorbed at $p / p_{0}=0.99$. [c] $t$-plot method.

\section{Mapping the Distribution of Cesium and Boron}

Understanding the location and distribution of both Cs and B species is instrumental to attain rationalization of observed results. However, efforts on determining boron distribution on Bmodified CsX catalysts are lacking. Tope et al.[22] reported, based on microscopy analysis, that $\mathrm{ZrB}_{2} \mathrm{O}_{5}$ interacts as particles with the external surface of CsX ones after physical mixing and calcination. Cs distribution studies are equally scarce; a homogeneous exchange degree throughout the material is normally assumed. In this respect, diffraction patterns in Fig. 1 indicate that Cs atoms occupy exchanged positions in the zeolite framework, whereas the decrease of the micropore volume due to the addition of boron (Table 1) suggests boron species may locate within the cages of the zeolite. Given the kinetic diameter of toluene $(0.58 \mathrm{~nm})$, styrene $(0.60 \mathrm{~nm})$, and ethylbenzene $(0.62 \mathrm{~nm})$, only boron centers located in the supercages of the faujasite structure $(0.735 \mathrm{~nm}$ as the maximum diameter for a freely diffusing molecule[25]) can interact directly with those species. However, these evidences do not necessarily account for all present species and provide no information on the (a)

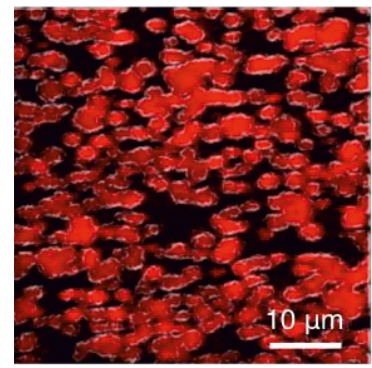

(b)

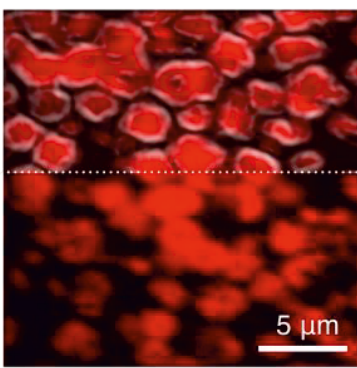

(c)
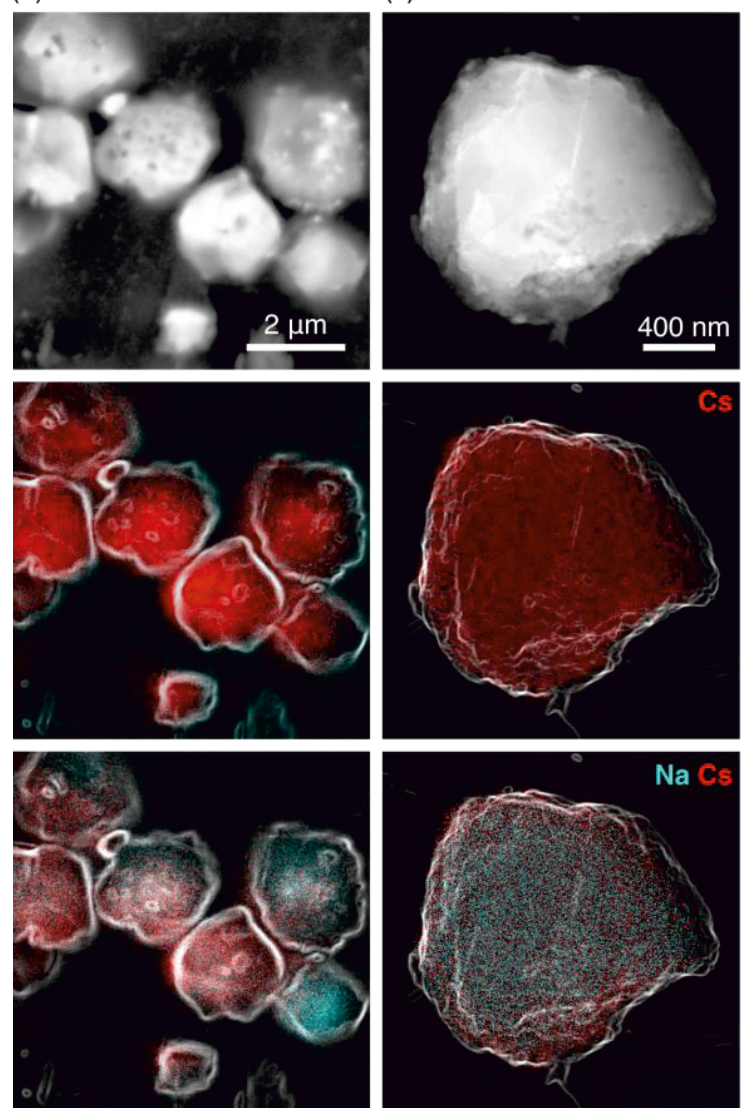

Figure 3. (a) Chemical maps of Cs acquired by ToF-SIMS at different magnifications, (b) representative BSE and (c) STEM images and associated elemental maps obtained from cross-sections of BCsX. White contours delimiting the edges of zeolite crystals, extracted from the corresponding Al maps, are superimposed in (a) as a visual aid. Unprocessed Al maps are presented in Fig. S3.

chemical homogeneity. With this aim, we studied nanometrically rough cross-sections of embedded materials prepared by broad ion-beam milling[18] by means of energy dispersive $X$-ray spectroscopy (EDX) coupled to scanning electron microscopy (SEM) and time-of-flight secondary ion mass spectrometry (ToFSIMS). The latter offers the benefits of visualization of light elements such as $\mathrm{B}[26,27]$ alongside a depth resolution of 1 $2 \mathrm{~nm}$ with a field of view from the nano to the millimeter size scale.

SEM-EDX analysis (Fig. 3b) confirmed the successful ion exchange in BCsX as reflected by the uniform Cs distribution 

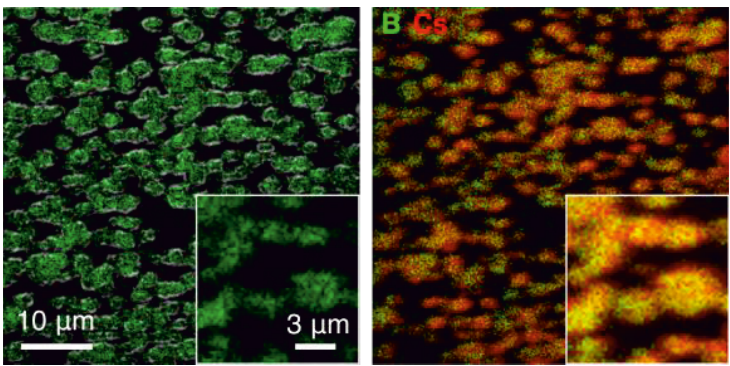

Figure 4. Chemical maps of $B$ acquired by ToF-SIMS from cross-sections of BCsX at different magnifications (left) and corresponding overlay with $\mathrm{Cs}$ distributions (right). White contours, extracted from the corresponding Al map, delimit the edges of zeolite particles in the left map as a visual aid. The unprocessed Al map is shown in Fig. S3. B maps comprise the combined signals from ${ }^{10} \mathrm{~B}^{+}$and ${ }^{11} \mathrm{~B}^{+}$isotopes. Each pixel in the inset maps accounts for ca. $185 \times 185 \mathrm{~nm}^{2}$

observed within the contour of the crystals, though some Na-rich areas are visible. However, the optimized EDX settings (10 kV) may result in significant penetration of the incident beam further influenced by the atomic mass of the excited atomsand thus, the depth and lateral resolution for $\mathrm{Cs}$ and $\mathrm{Na}$ may differ, being limited to the micrometer scale on each pixel. Given the typical diameter of the zeolite crystals analyzed, a different averaging of the $3 \mathrm{D}$ character should be expected for $\mathrm{Cs}$ and $\mathrm{Na}$ on the corresponding maps. Analysis by EDX coupled to scanning transmission electron microscopy (STEM) over thin cross-sections $(80 \mathrm{~nm})$ prepared by ultramicrotomy overcame this limitation and allowed the study of lateral variations in the composition with higher spatial resolution (Fig. 3c). Cs elemental maps confirmed its homogenous incorporation into the crystals, albeit a more careful analysis suggests a slight surface enrichment more evident when $\mathrm{Cs}$ and $\mathrm{Na}$ maps are superimposed. Parallel analyses by ToF-SIMS (Fig. 3a) exhibited good chemical homogeneity within the crystals, although a careful comparison revealed slight differences in the intensity of the signal among them. Particle contours extracted from the corresponding aluminum maps are used as a visual aid to locate zeolite crystals. Additionally, the correspondence between EDX and ToF-SIMS results suggests, in turn, that chemical distributions are not significantly altered upon exposure to the incident electron and ion beam, respectively. Lastly, from the comparison of the maps obtained from BCsX and CsX (Fig. S2), it can be concluded that the incorporation of B did not alter significantly the Cs distribution.

Representative elemental maps of the $\mathrm{B}$ distribution obtained from cross-sections of BCsX are shown in Fig. 4. In line with $\mathrm{N}_{2}$ sorption results, boron could only be detected within particles, confirming the introduction of the modifier into the micropore volume. Analyses at different magnifications disclosed that the concentration of B varied to a little extent among/within crystals, whereas the overlay of $\mathrm{Cs}$ and $\mathrm{B}$ chemical maps suggested local variations in the $\mathrm{Cs} / \mathrm{B}$ ratio at the submicrometer scale. Boron maps comprise the $\mathrm{B}^{+}$signal, since oxidic species $\mathrm{BO}_{\mathrm{x}}{ }^{-}$were not detected in the negative spectrum. This is at odds with reported results obtained from boric oxide/acid species.[28]

The presence of a Cs-rich rim suggested by STEM-EDX results in the crystals (Fig. 3c) could not be addressed in the ToF-SIMS (a)
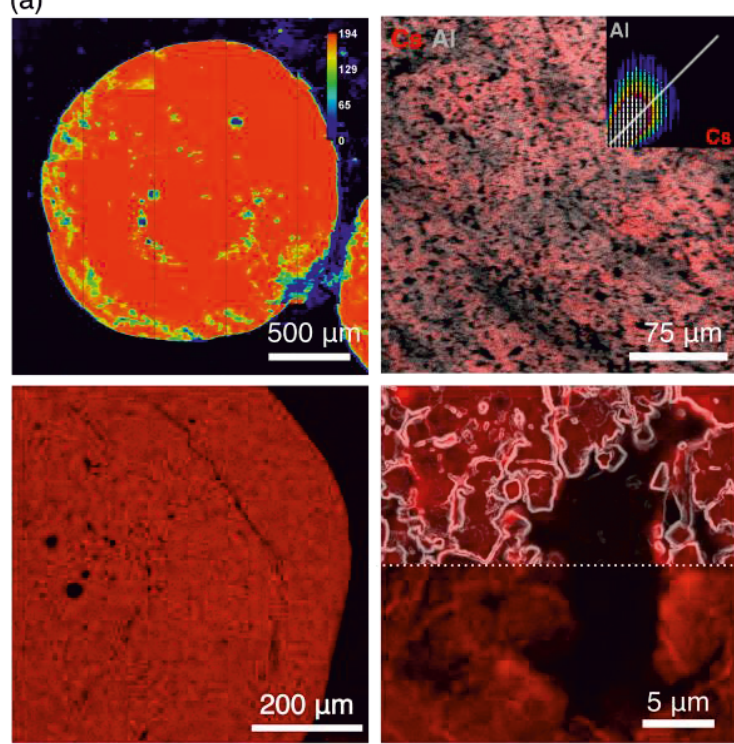

(b)
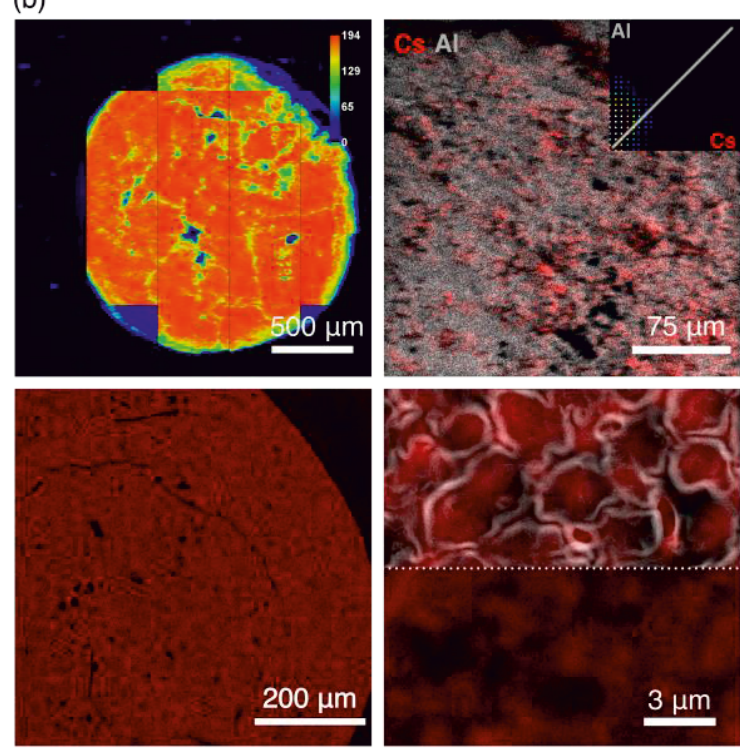

Figure 5. Chemical maps of Cs from cross-sections of (a) BCsX, and (b) $B C s_{L} X_{g}$ at different magnifications acquired by ToF-SIMS (top rows) and SEM-EDX (bottom rows). Color scales are associated to the number of counts. The ToF-SIMS Al maps serve as a visual aid to locate zeolite particles. Selected correlation plots in insets would converge to the bisecting white line in an ideal 1:1 correlation. Finer details on the Cs distribution at the granule scale are presented in Fig S6.

maps due to the inherent limitation in lateral resolution (ca. $100-200 \mathrm{~nm}$ ). A more detailed picture of the elemental distribution at the (near) surface emerged from $X$-ray photoelectron spectroscopy (XPS) analyses after successive $\mathrm{Ar}^{+}$ sputtering cycles. Depth profile analyses showed homogeneous distribution within the explored depth (estimated as $35 \mathrm{~nm}$ ) of all elements, including boron (Fig. S4a), which further supports the suitability of the boron incorporation procedure. Notwithstanding, a closer look at the Cs profile again revealed a slight surface enrichment of ca. $10 \mathrm{~nm}$ in thickness. Since $\mathrm{O} 1 \mathrm{~s}$ signals 

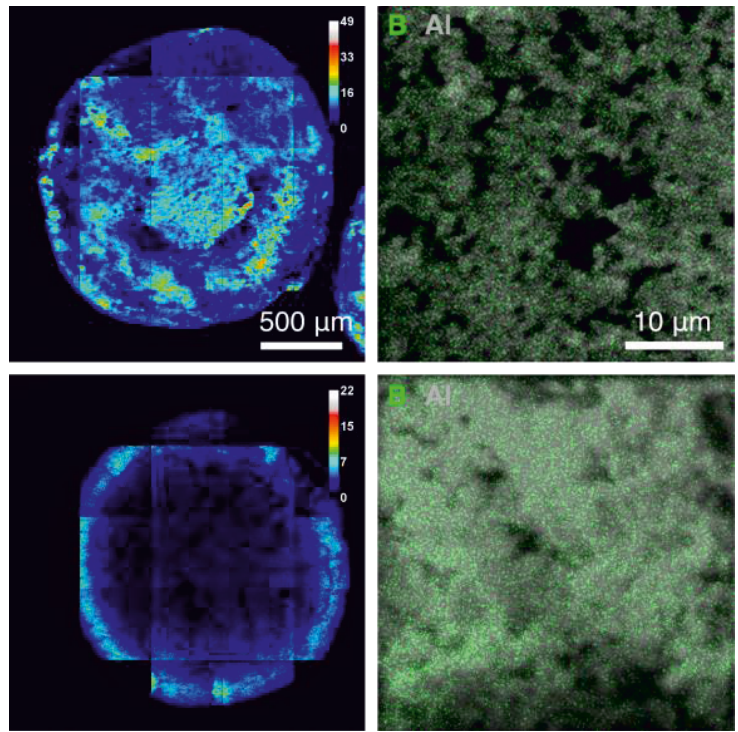

Figure 6. Chemical maps of $B$ acquired by ToF-SIMS from cross-sections of $\mathrm{BCsX}$, (top) and $\mathrm{BCs}_{\llcorner} \mathrm{X}_{\mathrm{g}}$ (bottom) at different magnifications. The ToF-SIMS Al maps serve as a visual aid to locate zeolite particles. Color scales are associated to the number of counts. B maps comprise the combined signals from ${ }^{10} \mathrm{~B}^{+}$and ${ }^{11} \mathrm{~B}^{+}$isotopes.

obtained before and after $\mathrm{Ar}^{+}$sputtering indicate contribution from oxides at the surface, as deduced from the corresponding peak shift (Fig. S4b) toward higher binding energies (i.e., lower basicity) the presence of oxidic Cs surface species is plausible. If catalytically available, $\mathrm{Cs}_{2} \mathrm{O}$ may play a role in directing the selectivity, as strong basicity is associated in literature to the transfer hydrogenation of styrene to ethylbenzene.[29] Analogous observations could be inferred from depth profiles performed over CsX (Fig. S4c and S4d).

We then turned to perform parallel visualization studies over cross-sections of the granulated catalysts. Inspection of ToFSIMS maps revealed fairly homogeneous distributions of $\mathrm{Cs}$ at the granule scale in $\mathrm{BCs}_{\mathrm{g}}$ and $\mathrm{BC} s_{\llcorner} \mathrm{X}_{g}$, in accordance with SEM-EDX observations (Fig. $\mathbf{5 a}$ and $\mathbf{5 b}$, respectively). Nevertheless, further insights arose from ToF-SIMS maps at higher magnification, where a better correlation between Cs and Al signals could be stablished for $\mathrm{BCs}_{\mathrm{g}}$ (see insets), and from the presence of $\mathrm{Na}$-rich areas in $\mathrm{BCs}_{\llcorner} \mathrm{X}_{\mathrm{g}}$ maps (Fig. S5). Additionally, a careful processing of Cs maps (Fig. S6) unveiled subtle differences in the distribution of $\mathrm{Cs}$ at the granule scale between $B C s X_{g}$ and $B C s_{L} X_{g}$. At this point, we note the divergence between closely matching Cs distributions and respective catalytic properties, underlining the high sensitivity of this system to a fully developed Cs exchange process. In stark contrast, a highly irregular boron distribution at the millimeter size scale (Fig. 6) was found irrespective of the material in all granules analyzed. Interestingly, maps obtained at the submicrometer scale revealed high local chemical homogeneity and the preferential location of boron in the zeolite host, resembling results obtained on BCsX (Fig. 4). In view of these results, severe zoning of catalytic properties within each granule was highly plausible. The milder promotion effect observed over $\mathrm{BCsX}_{\mathrm{g}}$ wrt. $\mathrm{CsX}_{\mathrm{g}}$ could thus be associated to the imperfect modification of the Cs-containing host granule. Overall, elemental maps obtained from granulated catalysts underscore the challenges associated to the scale up of modified technical zeolites, and more specifically, to the post-synthetic incorporation of modifying species.

\section{Spectroscopic Analysis of Cesium and Boron species}

After spatial characterization provided by visualization methods we aimed to clarify the speciation and chemical environment of Cs and B sites before and after exposure to different pretreatments relevant to typical side-alkylation conditions. Such identification is prerequisite for understanding their mechanistic role, however, prominent knowledge gaps persist in the literature in this respect. It is widely accepted that Cs speciation corresponds to the cationic form and its chemical environment to those associated to charge balancing positions.[29-31] However, speciation and chemical environment(s) associated to boron remain obscure, being normally assumed that boric oxide/acid particles populate the zeolitic cages.

A survey of the open literature on the synthetic routes and testing procedures more commonly reported for B-modified Csexchanged zeolite $X$ found that preparation procedures usually comprise a drying step at temperatures around $373 \mathrm{~K}$ (herein $383 \mathrm{~K}$ in air) after the incorporation of B. $[21,32,33]$ Since boric acid (frequently used as $B$ source) dehydrates into boric oxide at ca. $363 \mathrm{~K}$, which in turn melts at temperatures from 573 to $723 \mathrm{~K},[34]$ boric oxide is expected to be the predominant species in the dried fresh catalyst. Nonetheless, a common in situ pretreatment prior to reaction consists of exposing the material to temperatures between $723 \mathrm{~K}$ and $773 \mathrm{~K},[8,21,22,29,35,36]$ when boric oxide should be in liquid state. With this in mind, boron speciation and interaction with the host on the (near) surface of the catalyst in powder form was studied by XPS prior and after calcination $\left(773^{\circ} \mathrm{K}, \mathrm{N}_{2}, 2 \mathrm{~h}\right)$. Importantly, literature instructs on how binding energies for framework Si $2 p, \quad \mathrm{Al} 2 p$, and $\mathrm{O} 1 s$ core levels are highly dependent on the Si/Al value for $X$ zeolites (see Experimental Section for details).[37] Therefore, the analysis of relative positions of peaks is expected to yield more reliable results than that of their absolute values. In the first place, high resolution analysis around the B $1 \mathrm{~s}$ zone revealed a peak shift toward higher binding energies of about $0.5 \mathrm{eV}$ after calcination (Fig. 7b). Though modest, it is backed by opposite shifts observed on other elements such as Cs $3 d 5 / 2$ (Fig. 7a). The origin of the shift in the $\mathrm{B} 1 \mathrm{~s}$ signal might be a variation of the surface charge in the $\mathrm{B}_{2} \mathrm{O}_{3}$ species.[38] Alternatively, the shifts of the $C s 3 d_{5 / 2}$ and $B 1 s$ signals might suggest a possible mutual influence. After these observations, changes on the chemical state/environment of $\mathrm{B}$ and $\mathrm{Cs}$ induced by thermal treatments are conceivable.

As a complementary bulk technique to XPS, ${ }^{11} \mathrm{~B}$ magic angle spinning nuclear magnetic resonance $\left({ }^{11} B\right.$ MAS NMR) experiments applied to fresh BCsX unveiled that differently coordinated boron atoms coexist (Fig. 7d). The spectrum displays resonances in two chemical shift regions centered at ca. 2 and $15 \mathrm{ppm}$, ascribed to 4- and 3-coordinated boron respectively according to literature[39,40] and experiments over 
(a)

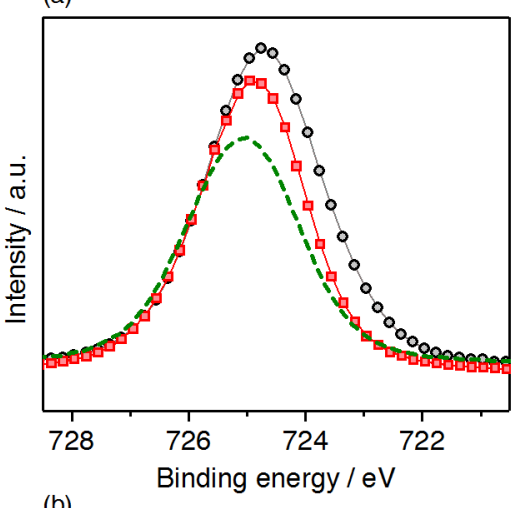

(b)

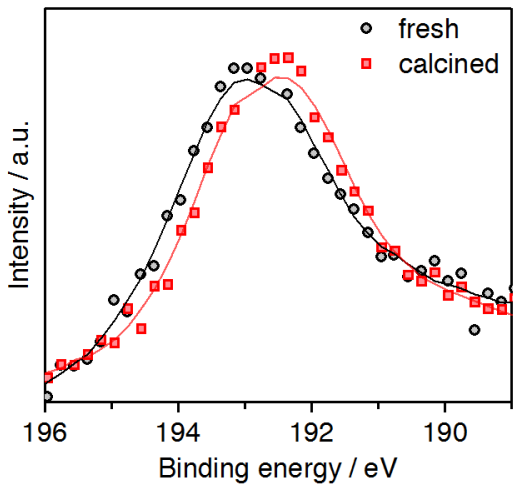

(c)

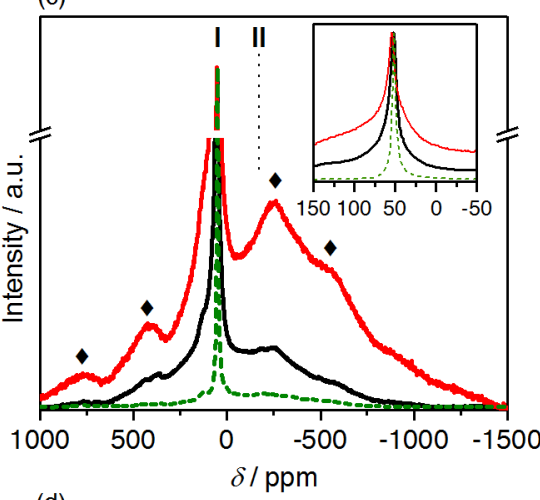

(d)

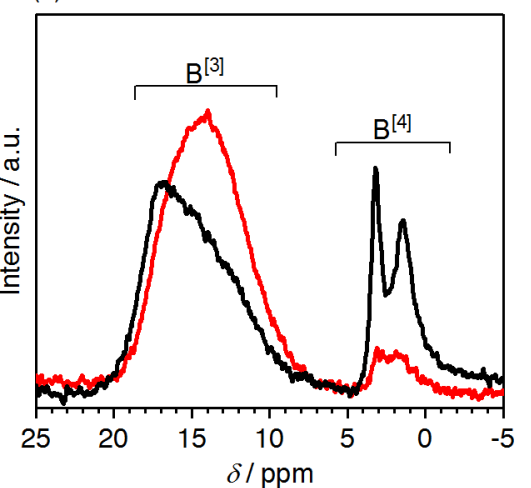

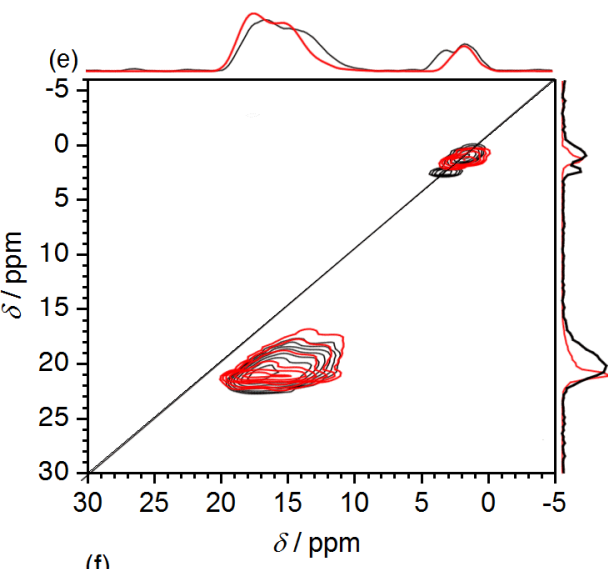

(f)

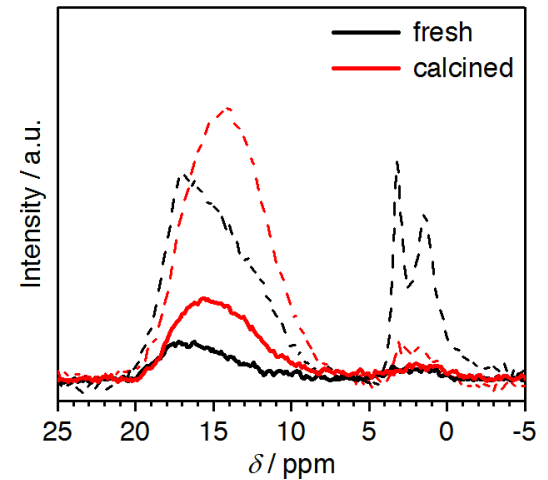

Figure 7. (a) $\mathrm{Cs} 3 d_{5 / 2}$ and (b) B1s XPS signals, (c) ${ }^{133} \mathrm{Cs}$ and (d) ${ }^{11} \mathrm{~B}$ MAS NMR spectra, (e) ${ }^{11} \mathrm{~B} 2 \mathrm{D}$ MQMAS NMR analysis, and (f) ${ }^{11} \mathrm{~B}-{ }^{1} \mathrm{H}$ cross polarization MAS NMR spectra of BCsX before and after calcination at $773 \mathrm{~K}$ in $\mathrm{N}_{2}$. The corresponding spectra for fresh CsX (dashed green) are shown for reference. In (c), spectra are normalized to peak I and diamond symbols indicate spinning side bands. In (d), expected chemical shift regions of 3- and 4-coordinate boron were determined by reference measurements (Fig. S7).

reference boron materials (Fig. S7a). More specifically, 4-coordinated boron exhibits two distinct peaks, which, in turn, must be ascribed to different chemical environments, as confirmed by 2D Multiple Quantum Magic Angle Spinning experiments (Fig. 7e). Consequently, the existence of two different coordinations with, at least, 3 different chemical environments around boron sites can be concluded for the fresh catalyst. Interestingly, calcined samples at $773 \mathrm{~K}$ in $\mathrm{N}_{2}$ displayed 1D and 2D NMR spectra closer to those obtained from boric oxide (Fig. S7b), though a detectable amount of 4-coordinated sites persisted (Fig. 7d). Further information was obtained from measurements over carefully dehydrated fresh samples $\left(373^{\circ} \mathrm{K}\right.$, vacuum, see Fig. S8b), which unveiled that the fraction of 4coordinated $\mathrm{B}$ giving rise to the acute peak at $3.5 \mathrm{ppm}$ over fresh $\mathrm{BCsX}$ interacts with $\mathrm{H}_{2} \mathrm{O}$, and changes toward a trigonal coordination upon dehydration. We note that $\mathrm{B}$ adds to sodium cations as preferential sites for water adsorption, [41] which may be related to the positive influence of co-feeding water and other compounds such as $\mathrm{H}_{2}$ and $\mathrm{CO}$ to direct the reaction toward the styrene product.[36]

4-coordinated $\mathrm{B}$ has been considered as a fingerprint to assess its incorporation into zeolite structures (commonly named as boralites). According to literature, B shows some flexibility to change its coordination influenced by thermal treatments, the presence of certain molecules, or compensation cations.[39,40,42-48] As an example, 4-coordinated framework $B$ under ambient conditions is described to change to 3coordinated upon dehydration,[48] in line with our results. Notwithstanding that thermal treatments may transform extrainto framework B, $[43,44,49]$ available reports do not provide elucidation on the extra- and/or framework nature of boron on Bmodified Cs-X catalysts for styrene/ethylbenzene production. In this respect, the change in the chemical state of $B$ suggested by XPS upon calcination (Fig. $\mathbf{7 b}$ ) is supported by the large depletion of 4-coordinated B (Fig. 7d). Supplementary ${ }^{11} \mathrm{~B}-{ }^{1} \mathrm{H}$ cross polarization NMR experiments (Fig. 7f) and its comparison with ${ }^{11} \mathrm{~B}$ MAS NMR spectra (dashed in the figure) allowed to estimate that ca. $1 / 8$ and $1 / 4$ of 3 -coordinated $B$ sites interact with hydrogen atoms in the fresh and calcined catalysts respectively, similarly to framework $B$ interacting with silanol groups.[50] However, the incorporation of boron to low Si/Al zeolite frameworks (1.3 in our case, see Table 1) has not been reported to our knowledge, which suggests an energetically deprived process. In this regard, B may also show a tetragonal coordination in extraframework positions in the presence of balancing cations - such as $\mathrm{Na}^{+}$or $\mathrm{Cs}^{+}-$, as occurs in the borax mineral (Fig. S7a) or due to partial decomposition of the acid into the oxide (though temperatures above $573 \mathrm{~K}$ are needed).[51] Presented evidences therefore indicate an extensive and complex interaction of $B$ with the zeolite host, 
compatible with extra- and/or framework positions and largely affected by operation conditions.

An equivalent investigation focused on Cs was also highly revealing (Fig. 7c). The prominent narrow peak (I, centered at ca. $50 \mathrm{ppm}$, see inset) is commonly reported for hydrated Cscontaining zeolites.[31,52,53] Nevertheless, the broad chemical shift range scanned in our study unveiled the presence of an unexpected broad bump (II, centered at ca. $-240 \mathrm{ppm}$ ), which has been reported, to our knowledge, only on some Cs salts. [54] Since reported isotropic resonances corresponding to $\mathrm{Cs}^{+}[53,54]$ and $\mathrm{Cs}_{2} \mathrm{O}[55]$ lie in the range from 40 to $-150 \mathrm{ppm}$ irrespective of the hydration state, and given the irrelevant contribution of the bump to the spectrum in CsX (dashed green), the bump can be reasonably assigned to some interaction with $\mathrm{B}$, as reported for $\mathrm{Na}^{+}$or $\mathrm{H}^{+}$on boralites.[39,40] Due to the small quadrupole coupling constants of this nucleus, such a broad signal is expected to arise only from a strong local electric field gradient. Notably, integration of I and II signals reveal II as the predominant environment around Cs species in BCsX, reflecting the marked influence of boron introduction in the chemical environment around Cs sites. In line with the detected shift around Cs $3 d_{5 / 2}$ energies in XPS measurements (Fig. 7a), the comparison between spectra before and after calcination clearly shows a large transfer from environment I to II, whereas mere dehydration (Fig. S8a) showed a much milder effect. These observations, together with the reported temperature-dependent $\mathrm{Cs}^{+}$mobility within zeolitic cages in (Cs, Na) faujasite-type zeolites[53] unveil a network of interactions developed by Cs and $B$ centers which is responsive to thermal conditions and adsorbates.

Based on these results, under more commonly reported operation temperatures (ca. $700 \mathrm{~K}$ ) we expect 3-coordinated $\mathrm{B}$ to predominate and interact with $\mathrm{H}^{+}, \mathrm{Cs}^{+}$, and possibly $\mathrm{H}_{2} \mathrm{O}$. Since $\mathrm{Cs}^{+}$sites are believed to stabilize the benzene ring and allow the initial hydrogen abstraction from methanol into formaldehyde, $[56,57]$ the modulation effect introduced by $B$ in the chemical environment of $\mathrm{Cs}^{+}$may have a decisive influence on tuning Cs-adsorbate interactions. In tandem, the appreciable fraction of B sites showing proton affinity upon calcination may also account for the modification of the basic strength. We note, however, that the identification of the chemical states of $B$ and Cs under operation conditions can be solely assessed by in situ observations, in view of the envisaged high sensitivity of the chemical configuration of active sites within the zeolite cages to the reaction temperature and composition of the inlet stream.

\section{Conclusions}

B-modified Cs-exchanged zeolite $X$ catalysts for the sidealkylation of toluene with methanol, both in powder and granule forms, were prepared by state-of-the-art synthetic procedures. Catalytic results over the powder catalyst did not transfer entirely to the granulated material. Advanced visualization studies by ToF-SIMS complemented by (S)TEM-EDX successfully unveiled $\mathrm{Cs}$ and $\mathrm{B}$ chemical homogeneity from the submicrometer to the millimeter size. A mostly homogenous Cs distribution across zeolite crystals in the powder was manifested, though a careful analysis revealed small variations in content among crystals and suggested slight nanometric surface enrichment. Concurrently, B was also homogeneously distributed within crystals. The irregular B distribution observed in the interior of the granules could be related to selectivity losses and manifested challenges associated to the post-synthetic scale up of modified zeolite catalysts. Detailed spectroscopic studies with strong focus on NMR over powder catalysts evidenced the profound impact of $B$ on the Cs-exchanged material. Results supported interactions with $\mathrm{Cs}^{+}, \mathrm{H}^{+}$, and $\mathrm{H}_{2} \mathrm{O}$ in the fresh material, where 3- and 4coordinated $\mathrm{B}$ centers coexist. Application of a thermal treatment typically used prior to reaction led to a spectroscopic fingerprint compatible with boric oxide and/or framework B, and strongly influenced the chemical environment around Cs cations. These findings pave the way toward a more profound understanding of the role of $B$, and thus represent a step ahead in pursuing the rational development of novel catalytic outliers. Concomitantly, they underscore the relevance of in situ studies to assess the observed network of interactions under operation conditions.

\section{Experimental Section}

Catalyst Preparation. Boron-modified cesium-exchanged zeolite $X$ catalysts were prepared in powder $(\mathrm{BCsX})$ and granule $\left(\mathrm{BCs}_{\mathrm{g}}\right)$ form. The alkali metal was introduced by ion exchange of commercial zeolite $X$ powder (13X, Acros Organics, Na-form) or binder-free granules (Köstrolith $®$ BFK, CWK, Na-form) by three consecutive treatments in a stirred aqueous $0.45 \mathrm{M} \mathrm{CsOH}$ solution $\left(40 \mathrm{~cm}^{3} \mathrm{~g}_{\text {zeolite }}{ }^{-1}\right)$ at $298 \mathrm{~K}$ for $3 \mathrm{~h}$. The solids were filtered, washed with deionized water until the $\mathrm{pH}$ of the filtrate was less than 8.5 , dried at $338 \mathrm{~K}$ overnight, and finally calcined at $773 \mathrm{~K}$ for $4 \mathrm{~h}\left(5 \mathrm{~K} \mathrm{~min}^{-1}\right.$ heating ramp). The Cs-exchanged materials were dispersed in a stirred acetone solution of boric acid $(0.09 \mathrm{M}$, $8.5 \mathrm{~cm}^{3} \mathrm{~g}_{\text {zeolite }}{ }^{-1}$ ) at room temperature for $2 \mathrm{~h}$, before heating to $343 \mathrm{~K}$ to remove the solvent by evaporation, and drying at $383 \mathrm{~K}$ for $2 \mathrm{~h}$. The targeted boron loading was $0.8 \mathrm{wt} . \%$. Dehydrated fresh catalysts were stored under vacuum prior to characterization. The effect of thermal treatment on the boron modifier was studied by further calcining the BCsX under $\mathrm{N}_{2}$ at $773 \mathrm{~K}$ for $2 \mathrm{~h}$. A catalyst with a lower Cs content $\left(B C s_{L} X_{g}\right)$ was analogously prepared except that the ion exchange was reduced to two consecutive treatments in a $0.2 \mathrm{M} \mathrm{CsOH}$ solution.

Basic Characterization. X-ray fluorescence (XRF) was conducted with an EDAX Orbis Micro-XRF analyzer equipped with a $\mathrm{Rh}$ source and operated at a voltage of $20 \mathrm{kV}$ and a current of $500 \mathrm{nA}$. X-ray diffraction (XRD) was undertaken in a PANalytical X'Pert PRO-MPD diffractometer with Bragg-Brentano geometry using Ni-filtered $\mathrm{CuK} \alpha$ radiation $(\lambda=0.1541 \mathrm{~nm})$. The patterns were recorded in the $2 \theta$ range of $5-70^{\circ}$ with an angular step size of $0.05^{\circ}$ and a counting time of $8 \mathrm{~s}$ per step. The granules were gently crushed prior to analysis. $\mathrm{N}_{2}$ isotherms at $77 \mathrm{~K}$ were measured in a Micromeritics TriStar II instrument. Granules or powder catalysts were degassed under vacuum at $573 \mathrm{~K}$ for $3 \mathrm{~h}$ prior to measurement. Temperature-programmed desorption of carbon dioxide ( $\mathrm{CO}_{2}$-TPD) was carried out using a Micromeritics Autochem II unit equipped with a thermal conductivity detector and coupled to an MKS Cirrus II mass spectrometer. Samples were dried (458 K, He, $60 \mathrm{~min}$ ) and subsequently exposed to 200 pulses $\left(0.5 \mathrm{~cm}^{3}\right.$ each) of pure $\mathrm{CO}_{2}$ in $\mathrm{He}\left(10 \mathrm{~cm}^{3} \mathrm{~min}^{-1}\right)$ at $318 \mathrm{~K}$. Finally, the desorption of $\mathrm{CO}_{2}$ was monitored while the temperature was ramped to $1173 \mathrm{~K}$ at $5 \mathrm{~K} \mathrm{~min}^{-1}$ in flowing $\mathrm{He}$.

Spectroscopic Analyses. X-ray photoelectron spectroscopy (XPS) was conducted using a Physical Electronics Quantum 2000 X-ray 
photoelectron spectrometer featuring monochromatic AlK $\alpha$ radiation, generated from an electron beam operated at $15 \mathrm{kV}$ and $32.3 \mathrm{~W}$, and a hemispherical capacitor electron-energy analyzer, equipped with a channel plate and a position-sensitive detector. Depth profiles were recorded upon $\mathrm{Ar}^{+}$sputtering at $2 \mathrm{kV}$ and using a $\mathrm{Ta}_{2} \mathrm{O}_{5}$ film as a reference for the determination of the depth. The low boron content required long acquisition times $(24 \mathrm{~h})$ in order to obtain acceptable signal-to-noise ratios. Charge compensation was performed by correction of Si $2 p$ measured energies to $102.5 \mathrm{eV},[37,58]$ corresponding to a molar $\mathrm{Si} / \mathrm{Al}=1.5(\mathrm{Si} / \mathrm{Al}=1.3$ from XRF measurements, Table S1). NMR to be (still) provided by RENE.

Visualization of elemental distributions. Scanning (SEM) and backscattered (BSE) electron micrographs and energy-dispersive X-ray (EDX) spectroscopy maps of internal cross-sections were acquired on a Quanta 200F instrument equipped with an Ametek EDAX Octane Super detector. Sample preparation involved embedding the granules or powder in a resin (LR white medium grade) and trimming and cutting the embedded sample with a high-precision diamond wheel saw (Leica TXP) to achieve a surface roughness of $<1 \mu \mathrm{m}$. The cross-sections were subsequently polished by exposure to an argon broad ion beam $(2 \mathrm{~h}$, $4 \mathrm{kV}$, Hitachi IM4000) and coated with a thin carbon film (ca. $5 \mathrm{~nm}$ ) to prevent charging. Scanning transmission electron (STEM) micrographs were acquired on a Talos F200X instrument operating at $200 \mathrm{kV}$ and equipped with a high-angle annular dark-field (HAADF) detector as well as energy-dispersive $\mathrm{X}$-ray spectrometer. Beam transparent sections $(80 \mathrm{~nm}$ thick) were obtained from the resin-embedded samples by ultramicrotomy and supported on copper grids covered with a continuous carbon film. Time-of-flight secondary ion mass spectroscopy (ToF-SIMS) was applied using an instrument from ION-TOF GmbH. was applied using an instrument from ION-TOF GmbH. During analysis a $\mathrm{Bi}_{1}{ }^{+}$primary ion beam $(25 \mathrm{keV})$ in combination with an electron flood gun for charge compensation was scanned over the surface with a $0.18 \mathrm{pA}$ target current.. Positive secondary ions generated by sputtering were extracted and analyzed with nominal resolution according to their respective charge-to-mass ratios. Post-processing analyses were performed using a home-made image processing software (DOI: 10.5281/zenodo.998576). Sample preparation included thermal pretreatment of the granules and powder at $783 \mathrm{~K}$ for $4 \mathrm{~h}$ in static air, followed by immersing them in a resin with low degassing rate under ultra-high vacuum conditions (Epothin 2, Buehler), leaving them for 30 min under vacuum to ensure good penetration, and finally hardening the resin at room temperature. The resulting disks were consecutively polished with three different grades of silicon carbide (P400, P1200, P2000) until the interior of the granules or powder particles were exposed. The last step comprised finishing of the surface with alumina paste $(0.05 \mu \mathrm{m})$ and cleaning in Millipore water for $2 \mathrm{~h}$ in an ultrasonic bath.

Catalyst Testing. Catalyst powders $(15 \mathrm{~g}, 0.5-2.5 \mathrm{~mm}$ sieve fraction) and granules $(20 \mathrm{~g}, 1.6-2.5 \mathrm{~mm}$ diameter) were tested in a stainless steel fixed bed reactor $(1.6 \mathrm{~cm}$ i.d.) with an offline GC (Agilent 7890B with an UCON capillary column $100 \mathrm{~m}$ long, $0.2 \mathrm{~mm}$ i.d. and $0.2 \mu \mathrm{m}$ film thickness) monitoring the outlet composition. Tests were conducted for $4 \mathrm{~h}$ at a temperature, $T=698 \mathrm{~K}$, a weight hourly space velocity, $W H S V=0.6 \mathrm{~h}^{-1}$ referred to toluene with a molar feed composition toluene:methanol $=1: 1$. In addition, $\mathrm{N}_{2}$ was also fed at $600 \mathrm{~cm}^{3} \mathrm{~h}^{-1}$ for the stable operation of the evaporator/plant, resulting in a total pressure, $P=0.1 \mathrm{MPa}$. Prior to operation, the temperature was ramped under a $\mathrm{N}_{2}$ atmosphere. Selectivity values are referred to toluene.

\section{Acknowledgements}

Thyssenkrupp Industrial Solutions AG for funding. ScopeM at ETH Zurich for access to its facilities.
Keywords: boron $\cdot$ heterogeneous catalysis $\bullet$ side-chain alkylation $\bullet$ styrene $\cdot$ ToF-SIMS

[1] J. Čejka, G. Centi, J. Perez-Pariente, W. J. Roth, Catal. Today 2012 179, 2-15.

[2] S. Mitchell, A. B. Pinar, J. Kenvin, P. Crivelli, J. Kärger, J. PérezRamírez, Nat. Commun. 2015, 6, 8633.

[3] W. J. Roth, P. Nachtigall, R. E. Morris, J. Čejka, Chem. Rev. 2014, 114, 4807-4837.

[4] P. Y. Dapsens, C. Mondelli, J. Perez-Ramirez, Chem. Soc. Rev. 2015, 44, 7025-7043.

[5] V. Valtchev, G. Majano, S. Mintova, J. Perez-Ramirez, Chem. Soc. Rev. 2013, 42, 263-290

[6] U. Deka, I. Lezcano-Gonzalez, B. M. Weckhuysen, A. M. Beale, ACS Catal. 2013, 3, 413-427.

[7] I. Lezcano-González, R. Oord, M. Rovezzi, P. Glatzel, S. W. Botchway, B. M. Weckhuysen, A. M. Beale, Angew. Chem. Int. Ed. 2016, 55, 5215-5219.

[8] N. Das, K. Pramanik, J. Indian Chem. Soc. 1997, 74, 701-704.

[9] J. Engelhardt, J. Szanyi, J. Valyon, J. Catal. 1987, 107, 296-306.

[10] M. D. Sefcik, J. Am. Chem. Soc. 1979, 101, 2164-2170.

[11] A. Philippou, M. W. Anderson, J. Am. Chem. Soc. 1994, 116, 57745783

[12] S. T. King, J. M. Garces, J. Catal. 1987, 104, 59-70.

[13] H. Itoh, A. Miyamoto, Y. Murakami, J. Catal. 1980, 64, 284-294.

[14] A. Simperler, R. G. Bell, A. Philippou, M. W. Anderson, J. Phys. Chem. B 2002, 106, 10944-10954.

[15] W. S. Wieland, R. J. Davis, J. M. Garces, Catal. Today 1996, 28, 443450.

[16] S. Mitchell, N.-L. Michels, J. Perez-Ramirez, Chem. Soc. Rev. 2013, 42, 6094-6112.

[17] S. Mitchell, N.-L. Michels, G. Majano, J. Pérez-Ramírez, Curr. Opin Chem. Eng. 2013, 2, 304-311.

[18] A. J. Martin, S. Mitchell, K. Kunze, K. C. Weston, J. Perez-Ramirez, Mater. Horizons 2017, 4, 857-861.

[19] H. S. Sherry, J. Phys. Chem. 1966, 70, 1158-1168.

[20] W. S. Wieland, R. J. Davis, J. M. Garces, J. Catal. 1998, 173, 490-500.

[21] C. Lacroix, A. Deluzarche, A. Kiennemann, A. Boyer, Zeolites 1984, 4, 109-111.

[22] B. B. Tope, W. O. Alabi, A. M. Aitani, H. Hattori, S. S. Al-Khattaf, Appl Catal., A 2012, 443-444, 214-220.

[23] N. Giordano, L. Pino, S. Cavallaro, P. Vitarelli, B. S. Rao, Zeolites 1987, 7, 131-134.

[24] A. Borgna, S. Magni, J. Sepúlveda, C. L. Padró, C. R. Apesteguía, Catal. Lett. 2005, 102, 15-21.

[25] International Zeolite Association, "Database of Zeolite Structures," can be found under http://www.iza-structure.org/databases/.

[26] F. Herzel, K.-E. Ehwald, B. Heinemann, D. Krüger, R. Kurps, W Röpke, H.-P. Zeindl, Surf. Interface Anal. 1995, 23, 764-770.

[27] N. Valle, J. Drillet, A. Pic, H.-N. Migeon, Surf. Interface Anal. 2011, 43 573-575.

[28] A. Benninghoven, C. A. J. Evans, R. A. Powell, R. Shimizu, H. A Storms, Secondary lon Mass Spectrometry SIMS-II. Proceedings of the Second International Conference, Held at Stanford, CA, USA, 27 - 31 August 1979., Springer, Berlin, 1980.

[29] W. O. Alabi, B. B. Tope, R. B. Jermy, A. M. Aitani, H. Hattori, S. S. AlKhattaf, Catal. Today 2014, 226, 117-123.

[30] M. Laspéras, H. Cambon, D. Brunel, I. Rodriguez, P. Geneste, Microporous Mater. 1996, 7, 61-72.

[31] H. Han, M. Liu, F. Ding, Y. Wang, X. Guo, C. Song, Ind. Eng. Chem. Res. 2016, 55, 1849-1858.

[32] H.-C. Liu, 1984, US 4483937 A

[33] D. Barthomeuf, V. Q. de Quivillic, 1991, US 5068483 A. 
[34] F. Sevim, F. Demir, M. Bilen, H. Okur, Korean J. Chem. Eng. 2006, 23, 736-740.

[35] Z. Zhang, W. Shan, H. Li, W. Zhu, N. Zhang, Y. Tang, J. Yu, M. Jia, W. Zhang, C. Zhang, J. Porous Mater. 2015, 22, 1179-1186.

[36] S. Chinta, J. L. Thorman, J. R.- Butler, 2014, US 2014/0257004 A1.

[37] M. Huang, A. Adnot, S. Kaliaguine, J. Am. Chem. Soc. 1992, 114, 10005-10010.

[38] C. W. Ong, H. Huang, B. Zheng, R. W. M. Kwok, Y. Y. Hui, W. M. Lau, J. Appl. Phys. 2004, 95, 3527-3534.

[39] C. Fild, D. F. Shantz, R. F. Lobo, H. Koller, Phys. Chem. Chem. Phys. 2000, 2, 3091-3098.

[40] C. Fild, H. Eckert, H. Koller, Angew. Chem. Int. Ed. 1998, 37, 25052507.

[41] C. E. A. Kirschhock, B. Hunger, J. Martens, P. A. Jacobs, J. Phys. Chem. B 2000, 104, 439-448.

[42] K. F. M. G. J. Scholle, W. S. Veeman, Zeolites 1985, 5, 118-122.

[43] L. Chen, M. Zhang, Y. Yue, C. Ye, F. Deng, Microporous Mesoporous Mater. 2004, 76, 151-156.

[44] M. B. Sayed, J. C. Védrine, J. Catal. 1986, 101, 43-55.

[45] H. Kessler, J. M. Chezeau, J. L. Guth, H. Strub, G. Coudurier, Zeolites 1987, 7, 360-366.

[46] G. Coudurier, A. Auroux, J. C. Vedrine, R. D. Farlee, L. Abrams, R. D. Shannon, J. Catal. 1987, 108, 1-14.
[47] V. R. Reddy Marthala, W. Wang, J. Jiao, Y. Jiang, J. Huang, M Hunger, Microporous Mesoporous Mater. 2007, 99, 91-97.

[48] S. J. Hwang, C. Y. Chen, S. I. Zones, J. Phys. Chem. B 2004, 108, 18535-18546.

[49] M. B. Sayed, A. Auroux, J. C. Védrine, J. Catal. 1989, 116, 1-10.

[50] H. Koller, C. Fild, R. F. Lobo, Microporous Mesoporous Mater. 2005 79, 215-224.

[51] M. Jimenez, S. Duquesne, S. Bourbigot, Thermochim. Acta 2006, 449 16-26.

[52] I. A. Ibarra, E. Lima, S. Loera, P. Bosch, S. Bulbulian, V. Lara, J. Phys Chem. B 2006, 110, 21086-21091.

[53] P. Norby, F. I. Poshni, A. F. Gualtieri, J. C. Hanson, C. P. Grey, J. Phys. Chem. B 1998, 102, 839-856.

[54] J. Skibsted, T. Vosegaard, H. Bildsøe, H. J. Jakobsen, J. Phys. Chem. 1996, 100, 14872-14881.

[55] J. C. Vedrine, in Zeolite Chem. Catal. Stud. Surf. Sci. Catal. (Eds.: H.G. Karge, H.K. Beyer, P.A. Jacobs, N.I. Jaeger, L. Kubelková, B. Wichterlová), Elsevier, 1991.

[56] A. E. Palomares, G. Eder-Mirth, M. Rep, J. A. Lercher, J. Catal. 1998, 180, 56-65.

[57] M. Huang, A. Adnot, S. Kaliaguine, J. Catal. 1992, 137, 322-332.

[58] M. L. Occelli, T. P. Debies, J. Catal. 1986, 97, 357-365. 


\section{Entry for the Table of Contents}

\section{ARTICLE}

Cs-exchanged zeolite $X$ modified with $B$ is the most promising catalyst for styrene production via the environmentally attractive side-chain alkylation of toluene with methanol. We applied advanced visualization tools to assess the influence of the scale up on the chemical homogeneity and performed detailed spectroscopic analyses to shed light on the speciation, chemical environment, and interaction associated to $\mathrm{Cs}$ and $\mathrm{B}$ centers.

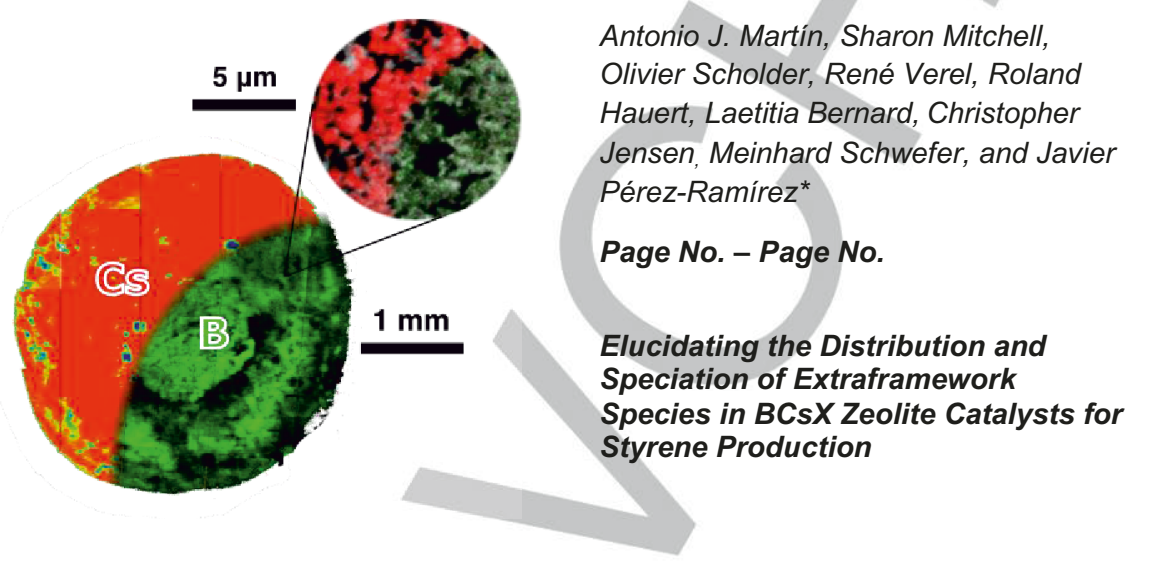

Antonio J. Martín, Sharon Mitchell, Jensen, Meinhard Schwefer, and Javier

Page No. - Page No

Species in BCsX Zeolite Catalysts for Styrene Production 